\title{
Correction to: Challenges of server consolidation in virtualized data centers and open research issues: a systematic literature review
}

\section{Reza Mohamadi Bahram Abadi ${ }^{1}$. Amir Masoud Rahmani ${ }^{2}$. Sasan Hossein Alizadeh ${ }^{3}$}

Published online: 16 December 2019

○) Springer Science+Business Media, LLC, part of Springer Nature 2019

\section{Correction to: The Journal of Supercomputing https://doi.org/10.1007/s11227-019-03068-1}

The wording of Sasan Hossein Alizadeh's name was incorrect. The correct wording is given here. The original article has been corrected.

Publisher's Note Springer Nature remains neutral with regard to jurisdictional claims in published maps and institutional affiliations.

The original article can be found online at https://doi.org/10.1007/s11227-019-03068-1.

Reza Mohamadi Bahram Abadi

mohamadi_re@yahoo.com

Sasan Hossein Alizadeh

s.alizadeh@itrc.ac.ir

1 Qazvin Branch, Faculty of Computer and Information Technology Engineering, Islamic Azad

University, Qazvin, Iran

2 Computer Engineering Department, Science and Research Branch, Islamic Azad University, Tehran, Iran

3 Department of Information Technology, ICT Research Institute (Iran Telecommunication Research Center), Tehran, Iran 